\title{
Prebiotic Mannan oligosaccharide pretreatment Improves Mice Survival Against Lethal Effects of Gamma Radiation by protecting GI Tract and Hematopoietic systems
}

\section{Sweta Sanguri}

IUAC: Inter-University Accelerator Centre

Damodar Gupta (D DAMODAR.GUPTA@GMAIL.COM )

DRDO Institute of Nuclear Medicine and Allied Sciences

\section{Research}

Keywords: Total body irradiation, gastrointestinal syndrome, hematopoietic syndrome, radiation countermeasure agents, Mannan oligosaccharide, radiation protection, sepsis

Posted Date: February 12th, 2021

DOl: https://doi.org/10.21203/rs.3.rs-212534/v1

License: (c) (1) This work is licensed under a Creative Commons Attribution 4.0 International License. Read Full License 


\section{Abstract}

Total body irradiation (TBI) results in critical injuries in a dose dependent manner that primarily damages highly proliferating tissues including hematopoietic stem cells (HSCs) and intestinal crypts stem cells etc. This may result in hematopoietic syndrome leading to bone marrow failure and gastrointestinal syndrome leading to chronic intestinal functional alterations. Death results from the gastrointestinal syndrome due to sepsis, bleeding, dehydration and multi-system organ failure. We demonstrate that the prebiotic mannan oligosaccharide (MOS) pretreatment substantially prolongs survival in both male and female mice when administered 2 hours prior to radiation either through oral or intraperitoneal route. The radioprotective efficacy of MOS was found to be age dependent and improves survival even in aged mice (12-13 month old). MOS pretreatment effectively abrogates radiation-induced hematopoietic injury, and accelerates recovery of lymphocytes and WBCs and alleviates depletion of circulatory blood cells. Results also illustrate that MOS pretreatment abolish crypt cell death and denudation of villi in comparison to the respective irradiated animals and ameliorates the overall radiation-induced damage to the GI system. MOS pretreatment facilitates intestinal recovery leading to enhanced animal survival demonstrating its protection efficacy against TBI induced mortality. Moreover, MOS pretreated animals show signs of accelerated recovery in terms of severity of radiation sickness symptoms including weight loss and completely abolish TBI associated mortality.

\section{Introduction}

Development of safe and effective radiation countermeasure approaches; including radio-protectors, mitigators, and therapeutics are crucial and vital for the management of prospective disaster scenarios comprising low and high dose radiation exposure[1]. Radiation exposure can result in mortality or can cause long-term adverse health effects depending upon the exposure dose, dose rate and time of exposure [2]. Acute radiation syndrome (ARS) arises mainly due to the intense enormity of injury to the actively proliferating cells including hematopoietic stem cells (HSCs) and intestinal crypts stem cells etc. resulting in hematopoietic syndrome (H-ARS; leading to bone marrow failure) and gastrointestinal syndrome (GI-ARS; leading to chronic intestinal functional alterations) respectively. High dose TBI can result in neurovascular acute radiation syndrome (NV-ARS) leading to death generally within 24-48 h. NVARS is considered fatal due to irreversible damage to organs. Therefore, only H-ARS and GI-ARS are being focused for the development of radiation countermeasures[3]. Radiation exposure induce damage to the intestinal crypt cells in the gastrointestinal tract, compelling crypt cells to undergo apoptosis within hours after lonizing radiation (IR) exposure [4]. Since GI tract is an extremely rapid cell turnover tissue, depletion of crypt cells result in homeostasis imbalance and restoration of intestinal villi is impaired, leading to loss of villi cellularity and denudation of the villi [5-6]. Consequently, other morphological changes including disruption of the epithelial barrier manifest along with compromised functional capacity leading to chronic intestinal functional alterations comprising GI-ARS. Hence, it is obligatory to identify efficient, medically safe, and affordable RCAs that can potentially prevent or manage both H-ARS and GI-ARS. 
Toll-like receptor (TLR) family is one of the imperative components of innate immune system, which is first line of defense against microbial invasion [7]. TLRs can recognize pathogens, molecular patterns and/or danger signals and induce immune signaling for evasion of infection. Stimulation of TLR2, 4, 5 or 9 by corresponding ligand(s) have been shown to reduce radiation-induced cell death in crypt cells, resulting in improved radiation-induced GI-ARS symptoms[7]. Consequently, different TLR ligands are currently under different stages of development as RCAs for ARS. Manipulation of TLR functions has been shown to activate NF-KB pathway and reduce radiation-induced cell death. Entolimod (CBLB502, a TLR5 agonist) has been granted both Fast Track and Orphan Drug status by US FDA during or after a radiation disaster to reduce risk of death. Entolimod has been shown to reduce radiation damage to both hematopoietic (HP) and gastrointestinal (GI) tissues and improve tissue regeneration $[2,8][9]$.

Mannan oligosaccharide (MOS) is a TLR agonist and is used as prebiotic nutritional supplement in several living organisms including farm animals, cattle's, pigs, dogs, chicken, fishes etc. for its gastrointestinal and immunological responses [10-11]. MOS is reported to improve health, growth status, and overall performance in animals [12-14]. It is known to support the gut microflora and stimulates epithelial barrier structure and functionality of intestinal mucosa [12]. MOS is shown to increase microvilli surface area and goblet cell numbers in small intestine of animals [15]. It stimulates the immune system of the host and has adsorbent capacity against toxins and it is non-toxic when administered orally, even in very large concentration [16-17]. Under in vitro conditions, we have demonstrated that MOS mediates alteration in mitochondrial physiology in immortalized normal cells and offer advantages in reducing biological effects of $y$-radiation in vitro and thereby enhances cell survival [18-19]. TLRs have been reported to express in humans and mice $[3,18,20]$, we intend to utilize the benefits of MOS supplementation against radiation induced ARS. Since mitochondrial respiratory activity is reported to decline during the natural ageing process, we investigated the effects of MOS pretreatment $(50 \mathrm{mg} / \mathrm{kg} /$ B.W i.p. and $200 \mathrm{mg} / \mathrm{kg} \mathrm{B.W}$. orally; $2 \mathrm{~h}$ prior to irradiation) on IR-induced injury in different age groups of BALB/c mice at lethal (7.5 Gy)and sub-lethal (3Gy and 5Gy) doses of TBI. In our preliminary experiments, we administered MOS intraperitoneally (50mg/kg/ B.W i.p; $2 \mathrm{~h}$ prior to irradiation) and observed $100 \%$ survival advantage in mice at lethal dose of TBI. MOS as a prebiotic is non-toxic orally and has beneficial effects in overall health of an organism. Remarkably, MOS pretreatment orally $(200 \mathrm{mg} / \mathrm{kg} \mathrm{B.W}$. orally; $2 \mathrm{~h}$ prior to TBl; $7.5 \mathrm{~Gy}$ ) also confer $100 \%$ radiation protection at lethal dose of TBI despite having a different biodistribution pattern than through intraperitoneal route as studied earlier [14]. TBI instigate bone marrow (BM) suppression resulting in loss of circulating blood cells. It also causes significant loss of viable crypt cells in the intestine, perturbs villus structure, disrupt mucosal layer integrity thereby compromising proper absorption of essential nutrients. The immune-suppression and thrombocytopenia associated with the H-ARS favors opportunistic infections and hemorrhage. MOS pretreatment to mice effectively minimizes radiation-induced hematopoietic and gastrointestinal injury, accelerates recovery of circulating blood cells, minimizes oxidative damage to important cellular biomolecules, restores intestinal integrity and consequently abrogates TBI-induced lethality.

\section{Materials And Methods}




\section{Chemicals}

All chemicals used in study were of analytical grade and were either procured from Indian manufacturer (SRL India, HiMedia chemicals) or obtained from Sigma Aldrich (St Louis, MO), Thermo Fisher Scientific Inc (USA) etc. Mannan oligosaccharide(MOS), 1,3,5-trihydroxybenzene, phloroglucinol, D-xylose, Ethylene diaminetetracetic acid (EDTA), BCA kit, hematoxylin, eosin, thiobarbituric acid, BSA, Mops, Sucrose, TBA, DTNB, NEM, neutral buffered formalin, decalcifying solution-Lite, were obtained from Sigma-Aldrich Chemical Co., St. Louis, MO, USA. Phosphate buffer saline (PBS), acetic acid, hydrochloric acid, and all other chemicals obtained were of analytical grade from SRL India. Reagents for hematology analyzer (Isotonac 3, Hemolynac 5, Hemolyzing Reagent, Hemolynac 3, Cleanac 3) were procured from Nihon Kohden, Japan.

\section{Mice}

Inbred BALB/c mice were obtained from the central experimental animal facility of Institute of Nuclear Medicine \& Allied Sciences (INMAS), Defence Research and Development Organization (DRDO). Both male and female mice of different age group viz. 8-12 weeks, 6-8 months and 12-13 months old acclimatized and healthy animals were chosen for studies. Mice were housed in the facility maintained at $21 \pm 2^{\circ} \mathrm{C}$ with $50 \% \pm 10 \%$ humidity on a $12 \mathrm{~h}$ light/dark cycle and were fed standard rodent feed (from Golden Feeds, Delhi, India) and water ad libitum. All surviving mice were euthanized at the completion of the observation period.

\section{Irradiation}

Mice were subjected to total body irradiation (TBI) in 60Co Gamma Teletherapy unit (Bhabhatron II, Panacea Medical Technologies, Bangalore, India) at a dose rate of 2.25-2.55 Gy/min. (dose rate of the 60Co Gamma irradiation source was calibrated using physical dosimetry). Mice were subjected to radiation exposure of either $3 \mathrm{~Gy}$ or $5 \mathrm{~Gy}$ and/or lethal dose of $7.5 \mathrm{~Gy}$ separately with or without MOS pretreatment.

\section{Preparation and administration of MOS}

MOS was dissolved $(20 \mathrm{mg} / \mathrm{ml}$ stock) in sterile phosphate buffered saline (PBS; $1 \mathrm{X}$ ) under aseptic conditions. MOS was administered (intra-peritoneal $50 \mathrm{mg} / \mathrm{kg}$ body weight or oral $200 \mathrm{mg} / \mathrm{kg}$ body weight separately as indicated) $2 \mathrm{~h}$ prior to total body irradiation (TBI) in mice for radioprotection efficacy studies.

\section{Survival Studies}

To study radio-protective efficacy of MOS, mice were divided into the following groups: Control (sham irradiated; vehicle treated), MOS alone, Radiation ( 3 or 5 or $7.5 \mathrm{~Gy}$ ) alone, and mice that received MOS $2 \mathrm{~h}$ before TBI ( 3 or 5 or $7.5 \mathrm{~Gy}$; $\mathrm{n}=8 /$ group). MOS was administered intra-peritoneal ( $50 \mathrm{mg} / \mathrm{kg}$ body weight) or orally $(200 \mathrm{mg} / \mathrm{kg}$ body weight) $2 \mathrm{~h}$ prior to TBI in a single fraction as per groups, as indicated. All 
animals were weighed and their well-being was inspected daily from the initiation of treatment to the end of the study.

\section{Evaluation of Biological effects of radiation}

To evaluate effects of MOS pretreatment in radiation protection and minimizing biological effects of radiation, mice were exposed to different doses of IR (3 Gy and $5 \mathrm{~Gy}$ ) separately. Mice were divided into the following six groups: Control (sham irradiated, vehicle treated), MOS alone (oral; $200 \mathrm{mg} / \mathrm{kg}$ body weight), radiation alone (3 Gy or $5 \mathrm{~Gy}$ alone), mice that received MOS $2 \mathrm{~h}$ before $3 \mathrm{~Gy}$ or $5 \mathrm{~Gy} \mathrm{TBI}$ ( $\mathrm{n}=8 /$ group). MOS was administered orally at $200 \mathrm{mg} / \mathrm{kg}$ body weight, $2 \mathrm{~h}$ prior to TBI (3Gy or $5 \mathrm{~Gy}$ ) in a single fraction as per groups. The mice were sacrificed on days $3,7,15$ and 40 as per ethical guidelines (by cervical dislocation) and tissues were collected. The tissues were washed in PBS and either fixed for histology or flash frozen in liquid $\mathrm{N}_{2}$, and stored for further assays.

\section{Peripheral blood analysis}

Blood were withdrawn from the retro-orbital plexus and collected in heparinized blood collection tubes (BD Biosciences, San Jose, CA) on days 3, 5, 15, and 21 following various treatments. Blood was mixed gently on a rotary shaker until acquisition and analysis for red blood cells, hemoglobin, platelets, leukocytes, and lymphocytes by using hematology analyzer (MEK-6400; Nihon Kohden, Japan) and data was generated using Data Management Software (DMS-Lite software).

\section{Histological examination of bone marrow}

Mice were euthanized humanely and femurs were isolated on days 3, 7, 15 and 40-post IR exposure or/and MOS treatment. Histological examination of bone marrow was done as described by Travlos et al with minor modifications[21]. Briefly, femurs were fixed in 10\% formalin, neutral buffered (Sigma) for 12$14 \mathrm{~h}$ at RT with gentle rocking followed by incubation in decalcifying solution-Lite (Sigma) at RT with gentle rocking for 14-16 h. Femurs were then washed thoroughly in tap water and thereafter processed for dehydration and paraffin blocks were made. The micro-sections $(3 \mu \mathrm{m})$ of tissue were prepared and stained with hematoxylin and eosin (H\&E). Slides were examined by microscopy and brightfield image acquisition was done using Cell imager, Optika Italy.

\section{Histological examination of small intestine}

Histological examination of small intestine was done as described by Morson et al [22] with minor modifications. Briefly, the mice were euthanized humanely and intestine of each animal was dissected, washed with PBS to remove intestinal contents (on days 3, 7, 15 and 40-post IR exposure). Following washing, jejunums were fixed in $10 \%$ neutral-buffered formalin (Sigma) at $37^{\circ} \mathrm{C}$ for $24 \mathrm{~h}$. The fixed tissue was thereafter processed for dehydration and paraffin blocks were made. The micro-sections $(5 \mu \mathrm{m})$ of tissue were prepared and placed on slides for staining with hematoxylin and eosin (H\&E). Slides were examined by microscopy and brightfield image acquisition was done using Cell imager, Optika Italy. Villus 
height and crypt depth were measured and compared with that of control. Villus height was determined by measuring the distance from the tip of the villus up to the crypt. Spatial scale of the active image was defined and presented in micrometer (calibrated unit, 2.55 pixels/micrometer) by converting pixels to $\mu \mathrm{m}$ using ImageJ software for mac (Version 1.50i, NIH USA).

\section{Crypt microcolony survival assay}

Non-serial transverse sections of jejunum were studied for the number of cells per crypt, and surviving crypt per T.S. Each section was separated from the previous one by a minimum of $50 \mu \mathrm{m}$ of tissue. Surviving crypts with $\geq 10$ cells for each T.S. were counted and results are expressed as number of surviving crypt/T.S. jejunum[23]. A surviving crypt was defined as one that had ten or more tightly packed strongly $\mathrm{H} \& \mathrm{E}$ stained cells (excluding Paneth cells). Only regions that were orientated correctly and did not contain Payer's patches were scored (Payer's patches influence both the number of crypts in a normal circumference and the ability of a crypt to survive insult). Number of cells per crypt was also counted and results are expressed as number of cells/crypt. Data were pooled from three to four separate T.S. of jejunum from each mouse. Only those crypts, which were seen directly against the inner muscle layer, were counted. All counts and measurements from each tissue specimen were obtained "blind" from a minimum of 4 coded sections.

\section{D-Xylose Absorption Assay}

To quantify absorption efficacy of intestine as a physiological indicator of mucosal barrier integrity in mice ( $n=8$ /group) after various treatments, a $D$-xylose uptake assay was performed at various time points $(0,3,7,10,15$ and 40 days post TBI). A $5 \% \mathrm{w} / \mathrm{v}$ solution of $D$-xylose $(100 \mu \mathrm{l} /$ mouse $)$ in deionized water was administered orally and blood samples were collected $2 \mathrm{~h}$ post administration. Blood was withdrawn from the retro-orbital plexus and collected in microtainer tubes (BD Microtainer Gold tube, BD Biosciences, San Jose, CA). Following 30 min coagulation at room temperature, the sera was well separated from the gel by 10 min-centrifugation at $10,000 \mathrm{~g}$, collected and stored at $-80^{\circ} \mathrm{C}$ for later study. Serum D-xylose concentration was determined according to Eberts et al. with minor modifications [24]. 5 $\mathrm{mL}$ phloroglucinol (1,3,5-trihydroxybenzene, Sigma Chemical Co., St. Louis, MO) reagent ( $0.5 \mathrm{~g}$ of phloroglucinol, $100 \mathrm{~mL}$ glacial acetic acid and $10 \mathrm{~mL}$ of conc. $\mathrm{HCl}$ ) was added to $50 \mu \mathrm{l}$ of plasma. This solution was heated to $100^{\circ} \mathrm{C}$ in a water bath for 4 min to allow optimum color development. After equilibration to room temperature, sample absorption was measured using spectrophotometer at $554 \mathrm{~nm}$ and D-xylose concentration in each serum sample was calculated using D-xylose standard calibration curve.

\section{Isolation of mitochondria}

Kidney and liver tissues stored at $-80^{\circ} \mathrm{C}$ were taken out and homogenate $(10 \%)$ was prepared in ice-cold isolation medium (0.3 $\mathrm{M}$ sucrose, $0.1 \% \mathrm{BSA}, 1 \mathrm{mM}$ EGTA, $5 \mathrm{mM}$ Mops, $5 \mathrm{mM} \mathrm{KH}_{2} \mathrm{PO}_{4}$, $\mathrm{pH} 7.4$ ) using a Potter Elvjham homogenizer and mitochondria were isolated using the method of Goel et al [25]. Briefly, the homogenate was centrifuged at $1000 \mathrm{~g}$ for $10 \mathrm{~min}$ at $4^{\circ} \mathrm{C}$. The supernatant was collected and 
centrifuged at $10000 \mathrm{~g}$ for $20 \mathrm{~min}$ at $4{ }^{\circ} \mathrm{C}$ to obtain the mitochondrial pellet. The mitochondrial pellet was washed three times with $50 \mathrm{mM}$ potassium phosphate buffer $(\mathrm{pH} 7.4)$ to remove traces of sucrose and integrity of mitochondria was determined by measuring the monoamine oxidase enzyme activity [26-27].

\section{Mitochondrial lipid peroxidation}

Thiobarbituric acid reactive substances (TBARS) were measured spectrophotometrically in liver and kidney homogenates as described by [28] with minor modifications. Briefly, mitochondrial protein (4 mg/ $\mathrm{mL}$ ) was mixed with an equal volume of Buege\& Aust reagent (TCA, $15 \%(\mathrm{w} / \mathrm{v})$ in $0.25 \mathrm{M} \mathrm{HCl} ; \mathrm{TBA}, 0.37 \%$ $(\mathrm{w} / \mathrm{v})$ in $0.25 \mathrm{M} \mathrm{HCl})$ and heated for $15 \mathrm{~min}$ in boiling water. After cooling, the precipitate was removed by centrifugation at $1000 \mathrm{~g}$ in a refrigerated centrifuge (Sigma 3-18K, St. Louis, MO, USA) for $10 \mathrm{~min}$ at room temperature. The absorbance of the supernatant was recorded at $532 \mathrm{~nm}$ (IMPLEN nanodrop, Germany) against a sample containing reagents but no sample. The concentration of TBARS was determined using an extinction coefficient of $1.56 \times 105 \mathrm{~mol}-1 \mathrm{~cm}-1$ and results are expressed as nMoles of MDA per mg of mitochondrial protein. Protein concentration in each sample was measured by using BCA kit(SigmaAldrich Chemical Co., St. Louis, MO, USA) as per manufacturers' protocol using bovine serum albumin (BSA) as standard.

\section{Thiol estimation}

Acid soluble thiol was measured spectrophotometrically in liver and kidney homogenates as described by Ellman with minor modifications [29]. Briefly, $0.3 \mathrm{ml}$ mitochondrial protein $(4 \mathrm{mg} / \mathrm{mL})$ was mixed with an equal volume of SDS (10\%) and mixed thoroughly. $2.4 \mathrm{ml}$ sodium phosphate buffer ( $5 \mathrm{mM}$ ) was added and the solutions were mixed properly. The background absorbance of the solution was recorded at 412 nm using spectrophotometer. $0.3 \mathrm{ml}$ DTNB $(1 \mathrm{mM})$ was then added and the solutions were incubated for $1 \mathrm{~h}$ at $37^{\circ} \mathrm{C}$ and absorbance was measured at $412 \mathrm{~nm}$. The concentration of sulfhydryls in the sample was determined using molar extinction coefficient of TNB $\left(14,150 \mathrm{M}^{-1} \mathrm{~cm}^{-1}\right)$ and 『results are expressed as nmol of TNB per mg of mitochondrial protein. Protein concentration in each sample was measured by using BCA kit (Sigma-Aldrich Chemical Co., St. Louis, MO, USA) as per manufacturers' protocol using bovine serum albumin (BSA) as standard.

\section{Statistical analysis}

All the data were analyzed using Graph Pad Prism (version 5.01) and is presented as mean \pm standard deviation (SD). Significance of difference between groups was determined by Student's t-test and Oneway or two-way ANOVA with Newman-Keuls' multiple composite-tests. Survival studies' data were analyzed using the Kaplan-Meier method followed by Mantel-Cox (log-rank) test for assessment of significant differences. Results were considered significant at $\mathrm{P}<0.05$.

\section{Results}


Survival studies performed on Balb $\mathrm{C}$ mice showed that all the mice exposed to lethal doses of gamma radiation (7.5 Gy) alone died within 14 days (LD-100/14). Treatment of mice with MOS alone (IP $50 \mathrm{mg} / \mathrm{kg} \mathrm{BW}$ or Oral $200 \mathrm{mg} / \mathrm{kg} \mathrm{BW}$ ) did not influence the survival of mice. Moreover, oral administration of MOS showed no toxicity in terms of survival up to $5 \mathrm{~g} / \mathrm{kg} \mathrm{BW}$. Pre-irradiation treatment of mice with MOS $(-2 h ; 50 \mathrm{mg} / \mathrm{kg}$ bw; IP) conferred remarkable protection of mice resulting in the $100 \%$ survival of mice (both males and female mice, age 8-12 weeks) as observed till 30 days(Fig. 1a; $p<$ $0.0001)$.Interestingly, pre-irradiation treatment of mice with MOS $(-2 \mathrm{~h} ; 200 \mathrm{mg} / \mathrm{kg}$ bw; orally) also conferred $100 \%$ survival of mice (both males and female, age 8-12 weeks and female, 6-8 months, Fig $1 \mathrm{~b}-\mathrm{c} ; \mathrm{p}<0.0001$ ) as observed till 30 days and thereafter also (up to 6 months) with respect to group exposed to radiation $(7.5 \mathrm{~Gy}$ ) alone. The radioprotective efficacy of MOS was found to be age dependent with $90 \%, 60 \%$ and $50 \%$ survival in 6-8 months male mice, $12-13$ months old female mice and 12-13 months old male mice respectively (Fig. 1c-d; $p<0.0001$ ) observed till 30 days. At 7.5 Gy TBI dose, the radiation alone group experienced absolute mortality and the entire cohort of animals died on (or before) 15-16 days post TBI accompanied with symptoms of radiation sickness such as weight loss, diarrhea, anorexia, and lethargy. The animals treated with MOS prior to TBI showed significantly less severity of symptoms or no symptoms at all. The studies were also performed to measure survival at sub-lethal dose of TBI (5Gy). Exposure of mice to $5 \mathrm{~Gy}$ radiation also found to reduce survival by $60 \%$ (LD-60/21) with respect to control group. Administration of MOS (male; $200 \mathrm{mg} / \mathrm{kg}$ bw orally; $-2 \mathrm{~h}$ ) conferred $100 \%$ protection with respect to $5 \mathrm{~Gy}$ alone $(\mathrm{p}<0.0001)$.

The result suggests that MOS treatment prior to radiation protects animal from deleterious effects of radiation and confers $100 \%$ survival when administered from either of the two routes.

\section{MOS pretreatment amends hematological indices in the peripheral blood post TBI}

The kinetics of hematopoietic recovery in sub-lethally irradiated mice treated with MOS was followed for 30 days post-TBI. MOS significantly increased survival from $60 \%$ to $100 \%$ in combination (MOS+5Gy) cohorts compared to TBI (5 Gy) group. Assessment of the peripheral blood for various hematological parameters exhibited significant decrease in peripheral blood components (Fig.2a-e). The results revealed that exposure to TBI significantly decreased the number of circulating leukocytes in animals exposed to TBI ( $3.87 \times 10^{3} \pm 0.35 \mathrm{cells} / \mu \mathrm{l}$ and $3.43 \times 10^{3} \pm 0.45 \mathrm{cells} / \mu \mathrm{l}$ in $3 \mathrm{~Gy}$ and $5 \mathrm{~Gy}$ TBI cohorts respectively) in comparison to $6.63 \times 10^{3} \pm 0.5$ cells/ $\mu$ in un-irradiated control cohorts, with nadir observed at day 15 postirradiation $\left(0.62 \times 10^{3} \pm 0.1\right.$ cells $/ \mu \mathrm{l}$ and $0.217 \times 10^{3} \pm 0.08$ cells $/ \mu \mathrm{l}$ in $3 \mathrm{~Gy}$ and $5 \mathrm{~Gy} \mathrm{TBI}$, respectively). Decrease in circulating leukocytes can compromise the health status of animals and can result in immunosuppression. Leukocyte levels did not recover till day 30 in the TBI mice. On the contrary, MOS pretreatment augmented the WBC count by accelerated recovery in the leukocyte counts at day 22 $\left(4.23 \times 10^{3} \pm 0.42 \mathrm{cells} / \mu \mathrm{l}\right.$ and $3.74 \times 10^{3} \pm 0.73 \mathrm{cells} / \mu \mathrm{l}$ in MOS $+3 \mathrm{~Gy}$ and MOS +5 Gygroup respectively), and recovered to almost normal levels by day 30 in animals of both MOS+3Gy and MOS+5Gygroup. The lymphocyte percentage significantly decreased at day $3(34.03 \pm 5.43 \%$ and $31.78 \pm 5.20 \%)$ and reached their nadir around day $5(20.20 \pm 0.73 \%$ and $19.82 \pm 2.85 \%)$ and did not recover until after day 30 postTBI (49.0 $\pm 1.97 \%$ and $43.50 \pm 3.95 \%)$, in both $3 \mathrm{~Gy}$ and 5 Gy cohorts, respectively (Fig. 2b). Contrarily, in 
MOS pretreated cohorts, the initial decrease in lymphocyte percentage was rapid till day 5 post $\mathrm{TBI}$, after which accelerated recovery was observed and approximately normal percentage was reached by day 30 post TBI. Exposure to TBI, in irradiated group resulted in initial gradual decrease in platelet count at day 3 $\left(784.07 \times 10^{3} \pm 32.42 \mathrm{cells} / \mu \mathrm{l}\right.$ and $\left.697 \times 10^{3} \pm 12.00 \mathrm{cells} / \mu \mathrm{l}\right)$ followed by a subsequent sharp decrease at day 5 , reached nadir ( $325.60 \times 10^{3} \pm 26.66$ and $259.10 \times 10^{3} \pm 47.92$ cells/ $\left.\mu \mathrm{l}\right)$ at day 15 post TBI and recovered levels were seen in 3 Gy and 5 Gy irradiated cohorts respectively, by day 30 post TBI (Fig 2e). Erythrocytes and hemoglobin were slower to reach their nadir (day 22), and both recovered to almost normal levels by day 30 (Fig2c-d) both in TBI and MOS+TBI cohorts. Hematopoietic suppression was significantly lesser in TBI mice pretreated with MOS in all studied parameters. Thus, these results suggest that MOS could be a potential countermeasure for the reduced number of circulating blood cells in irradiated animals.

\section{MOS pretreatment restores bone marrow cellularity in TBI mice}

TBI above a threshold dose induces hematopoietic injury and is characterized by depletion of the bone marrow cellular content $[7,30]$. Effects of MOS pretreatment on the radiation-induced damage to the bone marrow were analyzed by histological examination of the femurs on day 3, 7, 15 and 40 post TBI (3 Gy and $5 \mathrm{~Gy}$ ). In TBI mice, hematopoietic stem cells and vasculature is disrupted to a large extent, and results show dramatic decrease in bone marrow cellularity in TBI mice, variable cellularity with less than $50 \%$ hematopoiesis and dilated congested sinuses, till day 15 post 3 Gy and 5 Gy TBl; Fig. 3(ii-iii) in comparison to un-irradiated animals, that show hypercellular marrow, with more than $90 \%$ cellularity with trilineage hematopoiesis. Erythroid series is visible, myeloid series show complete maturation and megakaryocytes are adequate in number and morphology; Fig. 3(i). Contrarily, MOS pretreatment abrogated the radiation-induced cellular depletion to a large extent with cell numbers and cellular content almost similar to levels in the control animals, and accelerated recovery. The data corroborates well with peripheral blood analysis, and indicate that MOS pretreatment alleviates the TBI-induced BM suppression resulting in enhanced hematopoietic recovery.

\section{Histological examination of small intestine}

H\&E stained sections of the jejunum were analyzed on days 3, 7, 15 and 40-post irradiation. Jejuna from MOS treated animals prior to TBI (both 3 Gy and 5 Gy) and irradiated animals (both 3 Gy and 5 Gy TBI) showed shortening of the villi and loss of structural integrity at day 3 and 7 (Fig 4a1-a2). However, the villi blunting and loss of structure was significantly less in MOS-pretreated animals in comparison to the respective irradiated animals. Similarly, there was significant decline in crypt depth post TBI in comparison to un-irradiated control and the decrease was less in MOS-pretreated animals. MOS pretreated animals showed signs of accelerated recovery as demonstrated by the increase in villi length (427 $\pm 48.5 \mu \mathrm{m}$ and $359 \pm 31.09 \mu \mathrm{m}$, Fig. 5a), crypt depth (Fig. 5b) and the substantial decline in blunting in comparison to the irradiated group (villi length;237 $\pm 84.2 \mu \mathrm{m}$ and $206.66 \pm 23.094 \mu \mathrm{m}$, crypt depth) day 15 , post 3 Gy and 5 Gy TBI respectively. By day 40 the morphology of jejuna in both irradiated and MOSpretreated animals had returned to normal. The number of surviving and regenerating crypts per intestinal 
circumference was scored and the average per mouse and per group determined. The average viable crypts per T.S. of jejunum in the untreated control were about $120.5 \pm 3.56$ (Fig. 5c)MOS treatment alone exhibited non-significant changes in the number of crypts $(125 \pm 3.53,125 \pm 6.36,128 \pm 3.6$ and $123 \pm$ 4.7) than that of control (on day 3,day 7, day 15 and day 40 respectively). 3 Gy and 5 Gy cohorts exhibited reduced number of viable crypts to $81 \pm 2.82,82.5 \pm 3.53,86 \pm 4.24,100.5 \pm 3.53$ and $66 \pm 3.53$, $64 \pm 5.65,81 \pm 2.9,94.5 \pm 6.36$ on day $3,7,15$ and 40 post TBI respectively. Pre-irradiation administration of MOS in 3 Gy and 5 Gy TBI cohorts showed significantly higher number of viable crypts on day 3 (113 \pm 4.23 and $90 \pm 2.82$ ) and day 7 ( $94 \pm 2.82$ and $87 \pm 2.9$ ) respectively in comparison to irradiated control group.

Number of cells per crypts were counted and shown in Fig. 5d. The average cells per crypts of jejunum in the untreated control were about $35.5 \pm 2.32$. MOS treatment alone exhibited non-significant changes in the number of crypts than that of control in all the time points studied reduced The number of cells were reduced to $20 \pm 2.82,23.5 \pm 2.12,24 \pm 2.9,29.5 \pm 2.12$ and $17.5 \pm 2.12,16 \pm 1.41,20 \pm 2.9,24 \pm 2.2$ on days $3,7,15,40$ post( 3 Gy and 5 Gy) TBI respectively. MOS pretreatment showed significantly higher number of cells per crypt in MOS+3 Gy and MOS+5Gy cohorts on day $3(113 \pm 4.23$ and $90 \pm 2.82)$ and day 7 (94 \pm 2.82 and $87 \pm 2.9$ ) in comparison to irradiated cohorts respectively. Significant recovery was evident in MOS-pretreated cohorts in terms of villi height, crypt depth, number of surviving crypts and cells per crypts 15 days post TBI.

\section{Xylose absorption assay}

Functional regeneration and absorptive capacity of the intestines in TBI mice was determined by measuring intestinal absorption of D-xylose. Serum D-xylose level in non-irradiated group was $148 \pm$ $8.88 \mu \mathrm{g} / \mathrm{ml}$ and there was progressive reduction in xylose absorption in lethally irradiated mice $(63.66 \pm$ $11.84 \mu \mathrm{g} / \mathrm{ml})$, in comparison to MOS-pretreated mice $(112 \pm 9.84 \mu \mathrm{g} / \mathrm{ml}) 3$ days post TBl; Fig. 6 . Xylose absorption further declined in both irradiated cohorts $(43.44 \pm 4.9 \mu \mathrm{g} / \mathrm{ml})$ and MOS-pretreated cohorts $(90.33 \pm 9.29 \mu \mathrm{g} / \mathrm{ml})$ on day 7 post TBI. A time course study (1-40 days) showed significant recovery of xylose absorption at day $10(102 \pm 8.0 \mu \mathrm{g} / \mathrm{ml})$ and continued to improve tillday40 $(109 \pm 10.017 \mu \mathrm{g} / \mathrm{ml})$ in MOS-pretreated cohorts thereby, indicating the functional regeneration of intestine after radiation injury. The lethally irradiated cohorts exhibited surplus decline in xylose absorption at day 10 (35.33 \pm $5.51 \mu \mathrm{g} / \mathrm{ml})$ and day $15(31 \pm 3.6 \mu \mathrm{g} / \mathrm{ml})$ and no surviving animals after that animals), Irradiated animals were incapable of demonstrating adequate xylose absorption after radiation injury, further contributing to animal mortality.

\section{MOS pretreatment lowers MDA levels in the kidney and liver mitochondria}

lonizing radiation causes extensive damage to lipid component of biological membrane due to initiation of chain reaction of free radical formation [31]. Phospholipids along with protein components of the biological membrane are also equally vulnerable to the free radical mediated attack resulting in oxidative modification rendering them non-functional $[25,32]$. Lipid peroxidation leads to formation of mutagenic MDA, compromising membrane fluidity, integrity and biological functioning. 
Results show intensive increase in MDA concentration 3 days post 3 Gy and 5 Gy TBI mice kidney (72 \pm 4.24 and $86.5 \pm 6.36 \mathrm{nM} / \mathrm{L} / \mathrm{mg}$ of mitochondrial protein) in comparison to un-irradiated control (33 \pm 4.2$)$; Fig. 7. MDA concentration remained significantly high in TBI mitochondria (of mice kidney). MOS pretreatment in combination cohorts has shown significant decrease in MDA levels in the kidney mitochondria in comparison to that of irradiated animals at all the studied time points.

\section{MOS administration prior to TBI ameliorates free thiol levels in mitochondria}

Presence of thiols in biological system is of great significance in redox metabolism both as components of protein structures and as metabolic intermediates. Protein thiols play an important role in many cellular functions, including protein folding, enzyme catalysis, and metabolic regulation. Thiols are present as protein thiols and non-protein thiols and have ability to directly scavenge free radicals. Exposure to IR is known to deplete GSH and other thiols in animal tissues in dose dependent manner. Therefore, measurement of the biological thiols is important to investigate their roles in IR induced oxidative stress. Results show dramatic decrease in thiol concentration 3 days post 3 Gy and 5 Gy TBI mice kidney (3.05 \pm 0.778 and $2.25 \pm 0.354 \mathrm{nM} / \mathrm{L} / \mathrm{mg}$ of mitochondrial protein) in comparison to unirradiated control (6.050 \pm 0.35$)$; Fig. 8. Acid soluble thiol levels remained significantly lesser in TBI mitochondria (of mice kidney) at all time points studied in comparison to that of control. MOS pretreatment in combination cohorts has shown significant increased thiol levels in the kidney mitochondria in comparison to that of irradiated animals at all the studied time points. MOS administration prior to TBI improved thiol levels in mitochondria (kidney) of animals in comparison to that of irradiated group.

\section{Discussion}

Prebiotic MOS is reported to have beneficial effects in overall health of an organism, possess intestinal stimulatory capability, and immune modulation potential. And we have earlier reported in vitro radiation protection efficacy of MOS in normal cells with intact respiratory function [19]. This study focuses on demonstrating radioprotective effects of MOS, a prebiotic and understanding its role in reducing deleterious effects of TBI on hematopoietic and gastrointestinal system. Mannan pretreatment (IP $50 \mathrm{mg} / \mathrm{kg}$ BW or Oral 200 mg/kg BW, separately) confer 100\% survival advantage to 8-12 weeks old mice, (both male and female) against lethal dose of TBI (7.5 Gy) compared to 100\% mortality within 14 days after IR exposure alone group. (Fig. 1a-b). Moreover, improved survival (approximately 62\% and 50\%) in MOS pretreated BALB/c mice (12-13 months old female and male mice respectively) receiving lethal dose (7.5 Gy) of TBI was also observed (Fig. 1d). There was less decline and consequently prompt recovery of the radiation-induced loss of body weight in MOS pretreated cohort post total body irradiation (TBI) in comparison to irradiated animals (data not shown).

Hematopoietic stem cells and intestinal crypt stem cells are extremely sensitive to damage by IR, because of their highly proliferative nature [30]. Damage to these systems may contribute to the H-ARS or GI-ARS, or both with mortality as one of the end points [6]. Sensitivity of bone marrow against TBI has been well 
documented and pancytopenia is a major factor in radiation-induced morbidity and mortality [33]. We assessed the effects of MOS pretreatment on bone marrow and radiation-induced suppression in the number of circulating blood cells by exposing mice to $3 \mathrm{~Gy}$ and $5 \mathrm{~Gy} \mathrm{TBI}$ at days $3,7,15$ and 40 . There was massive ablation of cellular content of the bone marrow and consequent decrease in number of circulating blood cells after 3 Gy and 5 Gy TBI (Fig. 2a-e). Damage to hematopoietic stem cells result in depletion of peripheral blood lymphocytes and consequently enhances the susceptibility of organism to opportunistic secondary infections. Results reveal reduction in various hematological parameters post TBI and the baseline levels for most were never achieved in TBI mice. On the other hand, MOS modulated rapid recovery of the constituent parameters leading to attainment almost baseline levels of most peripheral blood cells by day 30(Fig. 2a-e). Bone marrow is the principal postnatal site of erythropoiesis and myelopoiesis in the mouse [1]. MOS pretreatment in mice reduced radiation induced damage to hematopoietic stem cells and instigated rapid restoration of bone marrow cellular content (Fig. 3) resulting in substantial increase the number of circulating blood cells (Fig. 2a-e). Stimulation of hematopoietic stem cells might be involved in promoting prompt recovery of hematopoietic system in comparison to irradiated group. IR poses damage to both gastrointestinal system and hematopoietic system and both of these losses can independently or synergistically result in mortality. It has been shown that doses that manifest GI-ARS also impacts bone marrow tremendously, and lowers ability of the body to manage the infections caused by intrusions in intestinal mucosal barrier [34]. Contrarily, findings from another study clearly separate the effects of radiation on the GI epithelium from those on the BM or BM-derived cells and have shown that the radio-sensitivity of the BM does not influence radiosensitivity of the GI epithelium [30]. The effects of MOS pretreatment on the radiation-induced damage to the GI system were analyzed by histological examination of the jejunum on day 3, 7, 15 and 40 post TBI. Results depict that MOS pretreatment followed by TBI minimizes crypt cell death and denudation of villi in comparison to the respective irradiated animals (Fig. 4 and 5a). Moreover, MOS pretreated animals showed signs of accelerated overall recovery as demonstrated by substantial decline in blunting and early restoration of normal morphology of small intestine.

Presence of thiols in biological system is of great significance in redox metabolism both as components of protein structures and as metabolic intermediates [35]. Thiols play an important role in many cellular functions, including protein folding, enzyme catalysis, and metabolic regulation [36]. Reduced glutathione (GSH) cysteine, cysteamine, and coenzyme A are major non-protein thiols in cellular pool [37-38]. Thiols are integral to a number of biological processes such as reducing deleterious oxidants, detoxification of xenobiotics and metabolism [38-39]. Biologically important protein bound sulfhydryls and low molecular weight thiols, including glutathione and cysteine have ability to detoxify lipid and other peroxides. Thiols have ability to directly scavenge free radicals and may act as cofactor for enzymes involved in management of oxidative stress. Exposure to IR is known to deplete GSH and other thiols in animal tissues in dose dependent manner. Therefore, we measured acid soluble thiols to investigate their roles in IR induced oxidative stress. MOS administration prior to TBI ameliorated acid soluble thiol levels in mitochondria (of liver and kidney) of animals in comparison to that of irradiated group (Fig. 8). lonizing radiation causes extensive damage to lipid component of biological membrane due to initiation of chain 
reaction of free radical formation [31]. Phospholipids along with protein components of the biological membrane are also equally vulnerable to the free radical attack resulting in oxidative modification rendering them non-functional [40]. Lipid peroxidation leads to formation of mutagenic MDA, compromising membrane fluidity, integrity and biological functioning [41]. MOS pretreatment in combination cohorts has shown significant decrease in MDA levels in the kidney and liver mitochondria in comparison to that of irradiated animals (Fig. 7). Mitochondria is an important cell organelle that is both potential source as well as target of ROS. Correspondingly, under in vitro system, we have demonstrated that MOS counter IR induced ROS through alteration in mitochondrial physiology, increase in MnSOD and $\mathrm{Cu} / \mathrm{ZnSOD}$ expression, and decrease in peroxidation of cardiolipin inside mitochondrial inner membrane [19]. As ageing progresses, there is more damage accumulation in mitochondria and there is decline in electron transport chain function. Since, mitochondrial respiratory capacity is known to decline with age, reduction in survival percent in mannan pretreated aged mice (50-60\% in 12-13 months old mice with respect to $100 \%$ survival in 8-12 weeks old mice) was well expected after TBI. Another independent study was done in our laboratory, to assess the effects of ionizing radiation on GI tract microflora in MOS treated mice post TBI. Mice gut microflora was cultured from the fecal matter followed by characterization of bacteria based on morphology and differential staining. The gut microflora largely remains unperturbed in MOS pretreated mice and there was decline in microflora type and number in TBI mice. The results of the study will be discussed in detail elsewhere (unpublished data). Results demonstrate that MOS ameliorates the radiation-induced damage to the hematopoietic and GI system, accelerates recovery leading to enhanced animal survival demonstrating its protection efficacy against TBI induced mortality (Fig.9).

In summary, MOS pretreatment effectively minimizes radiation-induced hematopoietic and gastrointestinal injury, accelerates recovery of circulating blood cells, minimizes oxidative damage to important cellular biomolecules, restores intestinal integrity and consequently abrogates TBI-induced lethality. Earlier, we have shown that TLR and mitochondrial ETC functions are inevitable in radioprotective efficacy exhibited by mannan. These observations clearly demonstrate the potential of mannan as a countermeasure agent to ameliorate biological effects of radiation. Abrogation of damage to both $\mathrm{Gl}$ and hematopoietic system and may play major role in enhanced recovery of organism and thereby improved overall survival. Further studies are necessary to unravel the mechanisms underlying decrease in the radiation-induced damage to stem cell compartments of tissue and accelerated repair of tissue damage by mannan pretreatment, besides its ability to abolish cellular oxidative stress. In recent years, numerous radiation countermeasure agents have been reported most of which are efficient but relatively toxic. Mannan, as a radiation countermeasure agent may be beneficial in case of planned radiotherapy events. However, present study was done on single strain of mice model and the results need to be validated in other more suitable animal model at pre-clinical levels.

\section{Declarations}

\section{Ethics approval and consent to participate}


All animal experiments were conducted in accordance to institutional guidelines, and the Institutional Animal Ethical Committee, Institute of Nuclear Medicine \& Allied Sciences (INMAS), Defence Research and Development Organization (DRDO). Present study is approved under institutional ethical committee number INM/IAEC/2016/11 and INM/IAEC/2018/02. All efforts were made to minimize suffering during experiments and experiments were carried out using protocols approved by the Institutional Animal Ethical Committee of INMAS, DRDO

\section{Consent for publication}

Both authors agree to publish this paper

\section{Availability of data and materials}

Not applicable

\section{Competing interests}

The authors declare that they have no competing interests.

\section{Funding}

This study was supported by Defence Research and Development Organization (DRDO), Ministry of Defence, India

\section{Authors' contributions}

SS and DG designed research; SS and DG performed research, analyzed data and wrote the paper. Both the authors read and approved the final manuscript.

\section{Acknowledgments}

Sweta Sanguri is grateful to CSIR for the award of research fellowship. We are grateful to Director, INMAS for providing opportunity to carry out this research work and Defence Research and Development Organization (DRDO), Ministry of Defence, India for providing necessary infrastructure and financial support for research. Cooperation and support of Experimental animal facility INMAS for providing and maintaining animals and Ms. Anjali Sharma for radiation exposure of cells using Bhabhatron II Irradiation facility is acknowledged.

\section{References}

1. Singh V, Gupta D, Almasan A: Development of novel anti-CD20 monoclonal antibodies and modulation in CD20 levels on cell surface: looking to improve immunotherapy response. Journal of cancer science \& therapy 2015, 7(11):347. 
2. Singh VK, Romaine PL, Newman VL, Seed TM: Medical countermeasures for unwanted CBRN exposures: part II radiological and nuclear threats with review of recent countermeasure patents. Expert Opin Ther Pat 2016, 26(12):1399-1408.

3. Singh VK, Seed TM: A review of radiation countermeasures focusing on injury-specific medicinals and regulatory approval status: part I. Radiation sub-syndromes, animal models and FDA-approved countermeasures. Int J Radiat Biol 2017, 93(9):851-869.

4. Potten CS, Merritt A, Hickman J, Hall P, Faranda A: Characterization of radiation-induced apoptosis in the small intestine and its biological implications. Int J Radiat Bio/ 1994, 65(1):71-78.

5. Ijiri K, Potten CS: The reestablishment of hypersensitive cells in the crypts of irradiated mouse intestine. Int J Radiat Biol Relat Stud Phys Chem Med 1984, 46(5):609-623.

6. Potten CS: The significance of spontaneous and induced apoptosis in the gastrointestinal tract of mice. Cancer Metastasis Rev 1992, 11(2):179-195.

7. Singh VK, Ducey EJ, Fatanmi OO, Singh PK, Brown DS, Purmal A, Shakhova VV, Gudkov AV, Feinstein E, Shakhov A: CBLB613: a TLR 2/6 agonist, natural lipopeptide of Mycoplasma arginini , as a novel radiation countermeasure. Radiation research 2012, 177(5):628-642.

8. Burdelya LG, Krivokrysenko VI, Tallant TC, Strom E, Gleiberman AS, Gupta D, Kurnasov OV, Fort FL, Osterman AL, Didonato JA et al: An agonist of toll-like receptor 5 has radioprotective activity in mouse and primate models. Science 2008, 320(5873):226-230.

9. Singh VK, Seed TM: Entolimod as a radiation countermeasure for acute radiation syndrome. Drug Discovery Today 2019, In Press(In press).

10. Momeni-Moghaddam P, Keyvanshokooh S, Ziaei-Nejad S, Parviz Salati A, Pasha-Zanoosi H: Effects of mannan oligosaccharide supplementation on growth, some immune responses and gut lactic acid bacteria of common carp (Cyprinus Carpio) fingerlings. Veterinary research forum : an international quarterly journal 2015, 6(3):239-244.

11. Hutsko SL, Meizlisch K, Wick M, Lilburn MS: Early intestinal development and mucin transcription in the young poult with probiotic and mannan oligosaccharide prebiotic supplementation. Poultry science 2016.

12. Razeghi Mansour M, Akrami R, Ghobadi SH, Amani Denji K, Ezatrahimi N, Gharaei A: Effect of dietary mannan oligosaccharide (MOS) on growth performance, survival, body composition, and some hematological parameters in giant sturgeon juvenile (Huso huso Linnaeus, 1754). Fish physiology and biochemistry 2012, 38(3):829-835.

13. Halas V, Nochta I: Mannan Oligosaccharides in Nursery Pig Nutrition and Their Potential Mode of Action. Animals : an open access journal from MDPI 2012, 2(2):261-274.

14. Sanguri S, Gupta D, Singh T, Singh AK: Biodistribution and scintigraphic evaluation of 99mTcMannan complex. Discoveries September 2016, 4:e65.

15. Santos EG, Costa FG, Silva JH, Martins TD, Figueiredo-Lima DF, Macari M, Oliveira CJ, Givisiez PE: Protective effect of mannan oligosaccharides against early colonization by Salmonella Enteritidis in 
chicks is improved by higher dietary threonine levels. Journal of applied microbiology 2013, 114(4):1158-1165.

16. Torrecillas S, Montero D, Caballero MJ, Robaina L, Zamorano MJ, Sweetman J, Izquierdo M: Effects of dietary concentrated mannan oligosaccharides supplementation on growth, gut mucosal immune system and liver lipid metabolism of European sea bass (Dicentrarchus labrax) juveniles. Fish \& shellfish immunology 2015, 42(2):508-516.

17. Madrigal-Santillan E, Alvarez-Gonzalez I, Marquez-Marquez R, Velazquez-Guadarrama N, MadrigalBujaidar E: Inhibitory effect of mannan on the toxicity produced in mice fed aflatoxin B1 contaminated corn. Archives of environmental contamination and toxicology 2007, 53(3):466-472.

18. Sanguri S, Gupta D: Role of Toll like Receptor (s) in Tumor Biology. J Tumor Med Prev 2017, 1(7).

19. Sanguri S, Gupta D: Mannan oligosaccharide requires functional ETC and TLR for biological radiation protection to normal cells. BMC cell biology 2018, 19(1):9.

20. Huhta H, Helminen O, Kauppila JH, Salo T, Porvari K, Saarnio J, Lehenkari PP, Karttunen TJ: The Expression of Toll-like Receptors in Normal Human and Murine Gastrointestinal Organs and the Effect of Microbiome and Cancer. The journal of histochemistry and cytochemistry : official journal of the Histochemistry Society 2016, 64(8):470-482.

21. Travlos GS: Normal structure, function, and histology of the bone marrow. Toxicol Patho/2006, 34(5):548-565.

22. Morson BC: Histopathology of the small intestine. Proc R Soc Med 1959, 52(1):6-10.

23. Potten CS: Protection of the small intestinal clonogenic stem cells from radiation-induced damage by pretreatment with interleukin 11 also increases murine survival time. Stem Cells 1996, 14(4):452459.

24. Eberts TJ, Sample RH, Glick MR, Ellis GH: A simplified, colorimetric micromethod for xylose in serum or urine, with phloroglucinol. Clinical chemistry 1979, 25(8):1440-1443.

25. Goel HC, Gupta D, Gupta S, Garg AP, Bala M: Protection of mitochondrial system by Hippophae rhamnoides L. against radiation-induced oxidative damage in mice. J Pharm Pharmacol 2005, 57(1):135-143.

26. Gupta D, Arora R, Garg AP, Goel HC: Radiation protection of mitochondrial system by Podophyllum hexandrum Royale in vivo. Mol Cell Biochem 2004, 266:65-77.

27. Gupta D, Arora R, Garg AP, Bala M, Goel HC: Modification of radiation damage to mitochondrial system in vivo by Podophyllum hexandrum: mechanistic aspects. Mol Cell Biochem 2004, 266(12):65-77.

28. Buege JA, Aust SD: Microsomal lipid peroxidation. Methods in enzymology 1978, 52:302-310.

29. Ellman GL: Tissue sulfhydryl groups. Arch Biochem Biophys 1959, 82(1):70-77.

30. Leibowitz BJ, Wei L, Zhang L, Ping X, Epperly M, Greenberger J, Cheng T, Yu J: lonizing irradiation induces acute haematopoietic syndrome and gastrointestinal syndrome independently in mice. Nature communications 2014, 5:3494. 
31. Cordeiro RM: Reactive oxygen species at phospholipid bilayers: distribution, mobility and permeation. Biochimica et biophysica acta 2014, 1838(1 Pt B):438-444.

32. Gupta D, Arora R, Garg AP, Goel HC: Radiation protection of HepG2 cells by Podophyllum hexandrum Royale. Mol Cell Biochem 2003, 250(1-2):27-40.

33. Kulkarni S, Singh PK, Ghosh SP, Posarac A, Singh VK: Granulocyte colony-stimulating factor antibody abrogates radioprotective efficacy of gamma-tocotrienol, a promising radiation countermeasure. Cytokine 2013, 62(2):278-285.

34. Booth C, Tudor G, Tudor J, Katz BP, MacVittie TJ: Acute gastrointestinal syndrome in high-dose irradiated mice. Health physics 2012, 103(4):383-399.

35. Liu Y, Song Y, Rockenbauer A, Sun J, Hemann C, Villamena FA, Zweier JL: Synthesis of trityl radicalconjugated disulfide biradicals for measurement of thiol concentration. The Journal of organic chemistry 2011, 76(10):3853-3860.

36. Klomsiri C, Karplus PA, Poole LB: Cysteine-based redox switches in enzymes. Antioxidants \& redox signaling 2011, 14(6):1065-1077.

37. Biaglow JE, Varnes ME, Clark EP, Epp ER: The role of thiols in cellular response to radiation and drugs. Radiation research 1983, 95(3):437-455.

38. Poole LB: The basics of thiols and cysteines in redox biology and chemistry. Free radical biology \& medicine 2015, 80:148-157.

39. Mari M, Colell A, Morales A, von Montfort C, Garcia-Ruiz C, Fernandez-Checa JC: Redox control of liver function in health and disease. Antioxidants \& redox signaling 2010, 12(11):1295-1331.

40. Orrenius S, Gogvadze V, Zhivotovsky B: Mitochondrial oxidative stress: implications for cell death. Annual review of pharmacology and toxicology 2007, 47:143-183.

41. Gulbahar O, Aricioglu A, Akmansu M, Turkozer Z: Effects of radiation on protein oxidation and lipid peroxidation in the brain tissue. Transplantation proceedings 2009, 41(10):4394-4396.

\section{Figures}



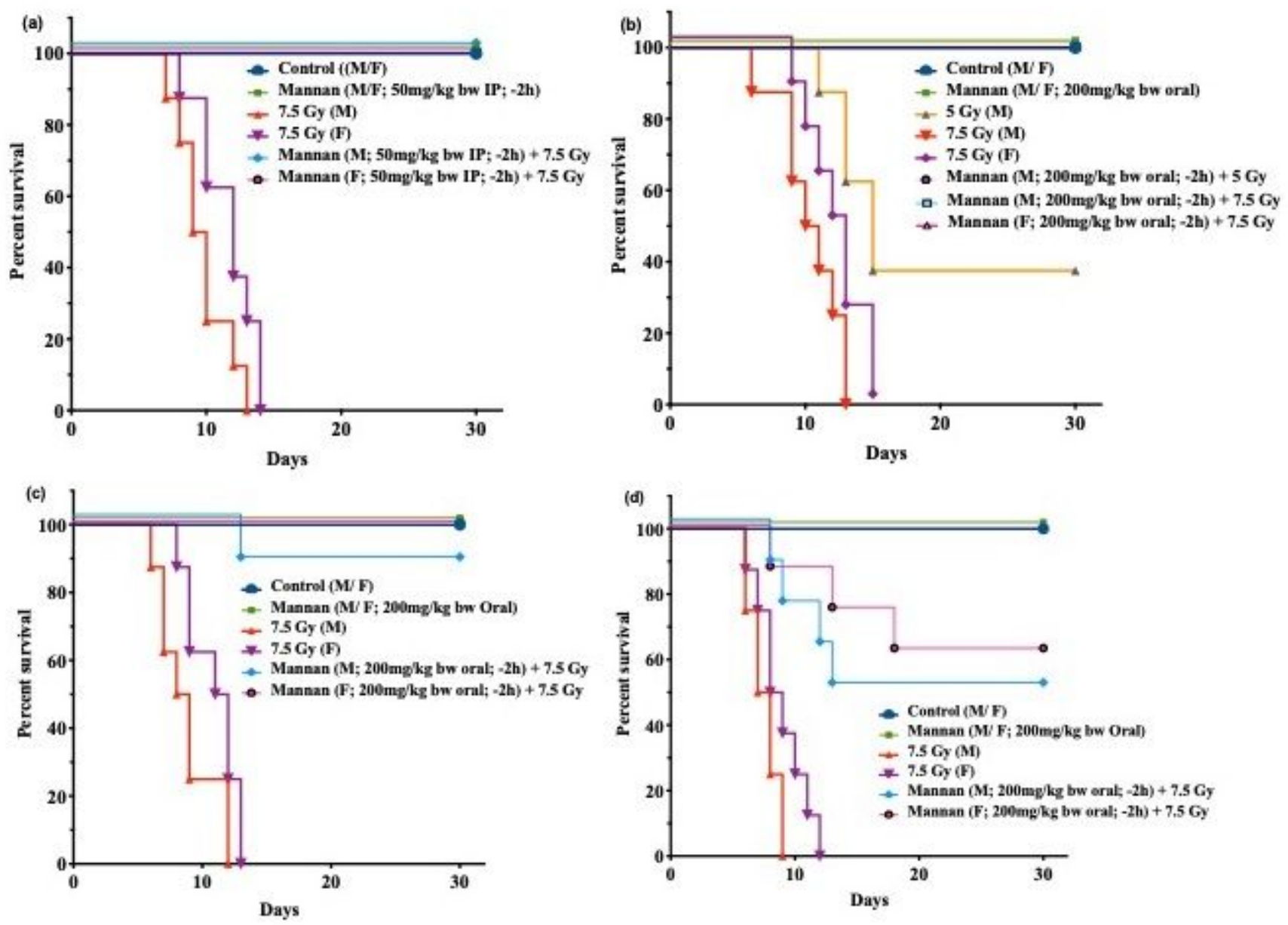

Figure 1

(a-b): MOS pretreatment protects mice from TBI-induced lethality Protective effects of MOS (i.e. administered $2 \mathrm{~h}$ prior to irradiation) against lethal TBI (7.5 Gy). (a)Mice (8 to 12 weeks old, both male and female) were injected MOS (50mg/kg/ B.W.; i.p.) and irradiated 2 hours post treatment. (b) Protective effects of MOS (i.e. administered Oral $200 \mathrm{mg} / \mathrm{kg} \mathrm{B.W.} \mathrm{;} 2 \mathrm{~h}$ prior to irradiation) against lethal TBI (7.5 Gy) and sub-lethal TBI (5Gy). Mice (8 to 12 weeks old, both male and female) were administered MOS orally and irradiated 2 hours post treatment. Kaplan-Meier survival curve depicts the 30 -day survival $(n=8$ in all the groups) (c) Mice (6-8 months old, both male and female) were administered MOS orally $(200 \mathrm{mg} / \mathrm{kg}$ B.W.) and irradiated 2 hours post treatment. (d) Mice (12-13 months old, male) were administered MOS orally $(200 \mathrm{mg} / \mathrm{kg} \mathrm{B.W}$. and irradiated 2 hours post treatment. Kaplan-Meier survival curve depicts the $30-$ day survival ( $\mathrm{n}=8$ in all the groups). 

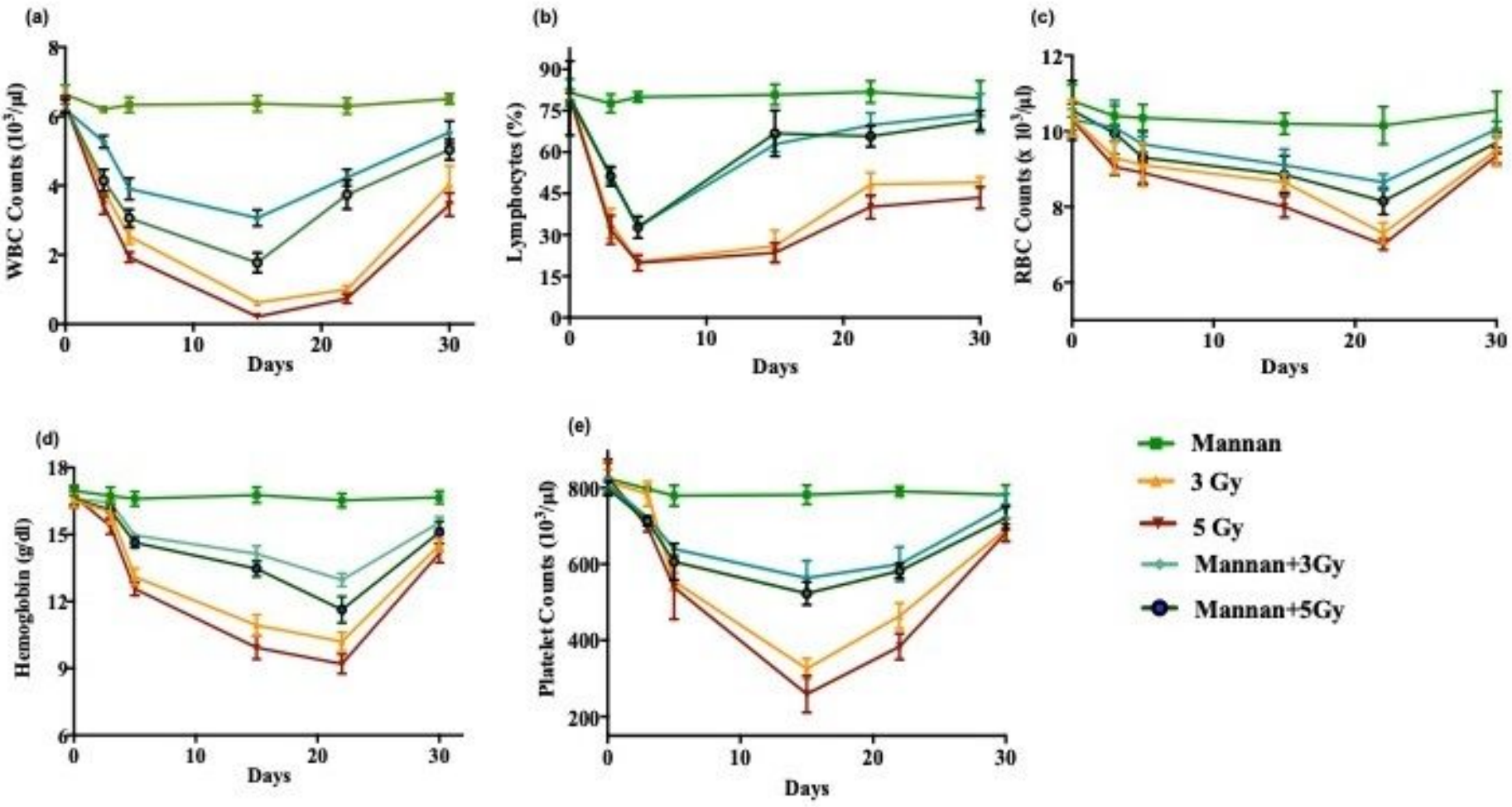

\section{Figure 2}

(a-e): MOS mediated alterations in the hematological indices in the peripheral blood. Mice were treated with MOS and/or subjected to exposure of radiation ( $3 \mathrm{~Gy}$ and $5 \mathrm{~Gy}$ ) assessed for blood cell parameters as described in materials and methods. Blood counts showing (a) WBC (b) Lymphocyte (c) RBC (d) hemoglobin and (e) Platelets at days $3,5,15,22$ and 30 post TBI. $(n=10)$. Error bars indicate SD. 


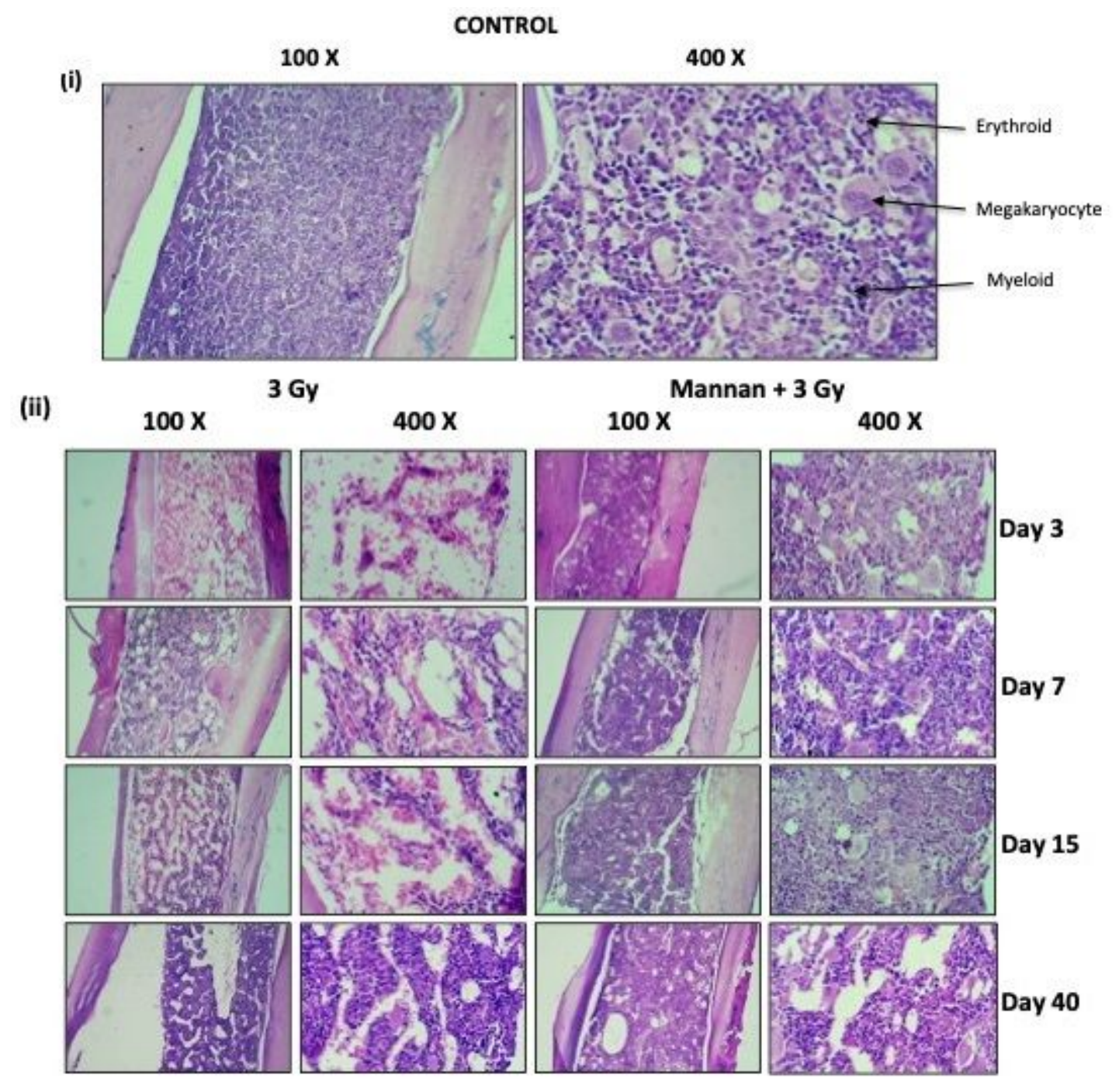

Figure 3

Histological examination of bone marrow Mice were treated with MOS and/or subjected TBI (3 Gy and 5 Gy) assessed for histological examination of small intestine on days 3, 7, 15 and 40-post MOS treatment and/or TBI as described in materials and methods. (i) Representative image of H\&E stained femur section of un-irradiated control mice at $100 \mathrm{X}$ and $400 \mathrm{X}$ magnification. (ii) Representative image of H\&E stained femur section of $3 \mathrm{~Gy} \mathrm{TBI}$ and $3 \mathrm{~Gy}+\mathrm{M}$ mice at $100 \mathrm{X}$ and $400 \mathrm{X}$ magnification (iii) Representative image of H\&E stained femur section of $5 \mathrm{~Gy} \mathrm{TBI}$ and $5 \mathrm{~Gy}+\mathrm{M}$ mice at $100 \mathrm{X}$ and $400 \mathrm{X}$ magnification. 


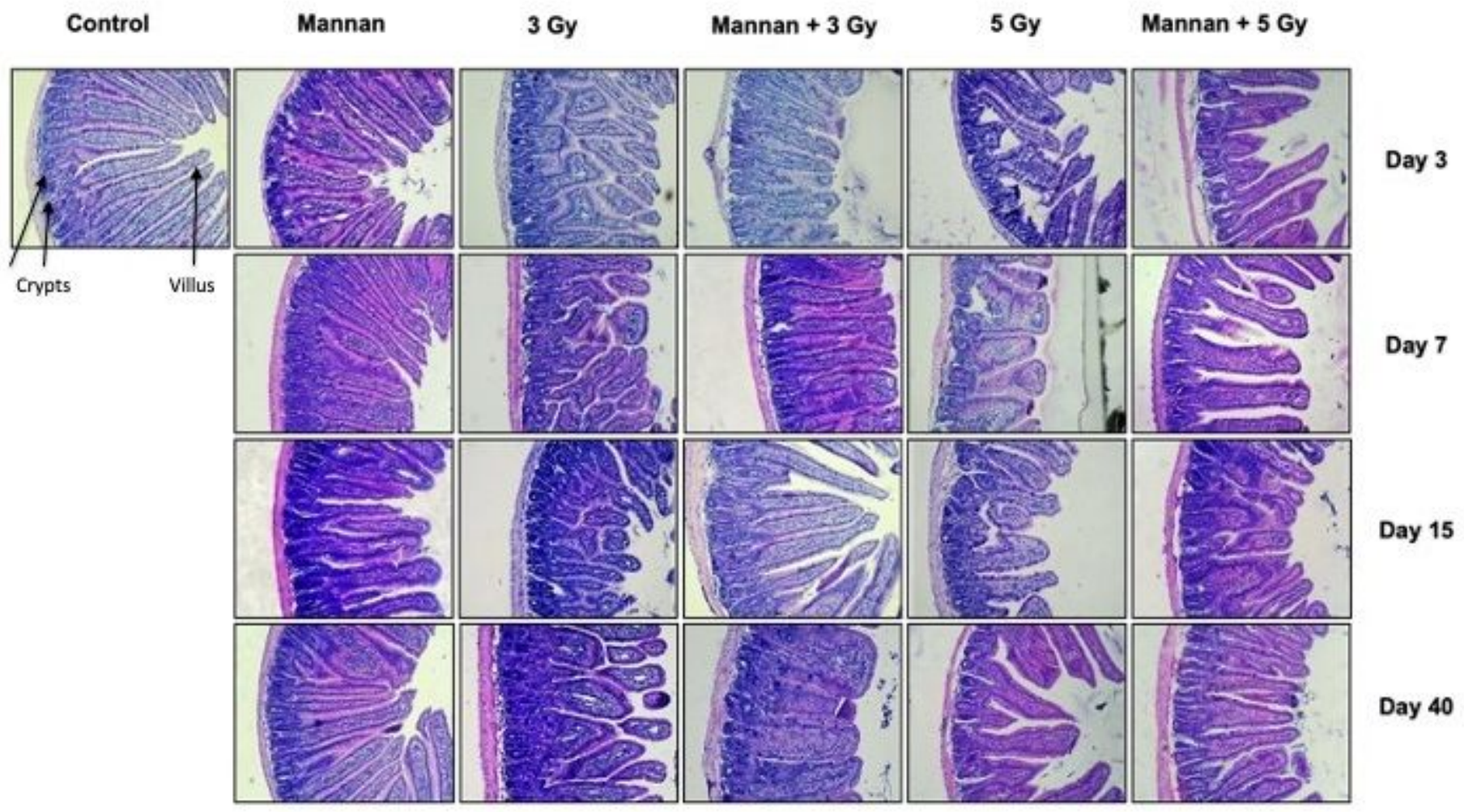

Figure 4

(a1): Histological examination of small intestine Mice were treated with MOS and/or subjected TBI (3 Gy and $5 \mathrm{~Gy}$ ) assessed for histological examination of small intestine on days 3, 7, 15 and 40-post MOS treatment and/or TBI as described in materials and methods. (a) Representative images of H\&E stained T.S. of jejuna from control, MOS treated, $3 \mathrm{~Gy}$ TBI and $3 \mathrm{~Gy}+\mathrm{M}$ mice at $100 \mathrm{X}$ magnification. 
(a)

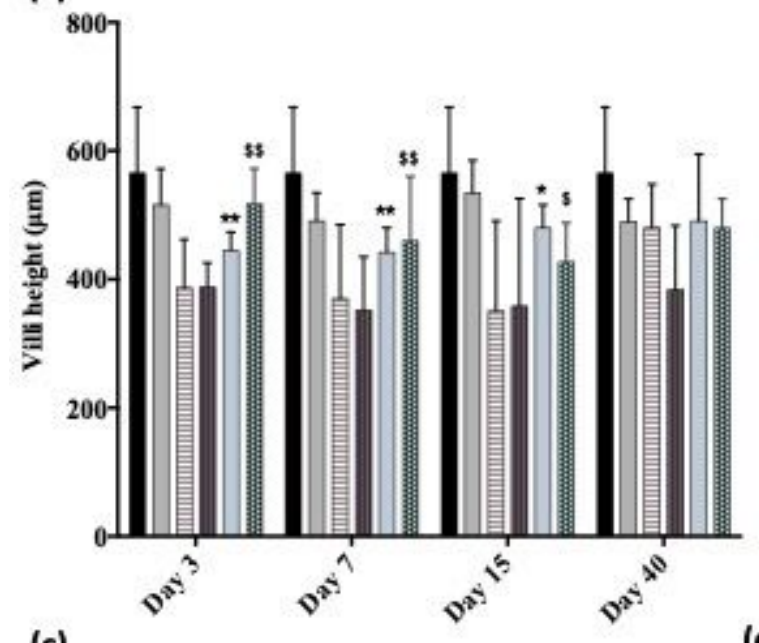

(c)

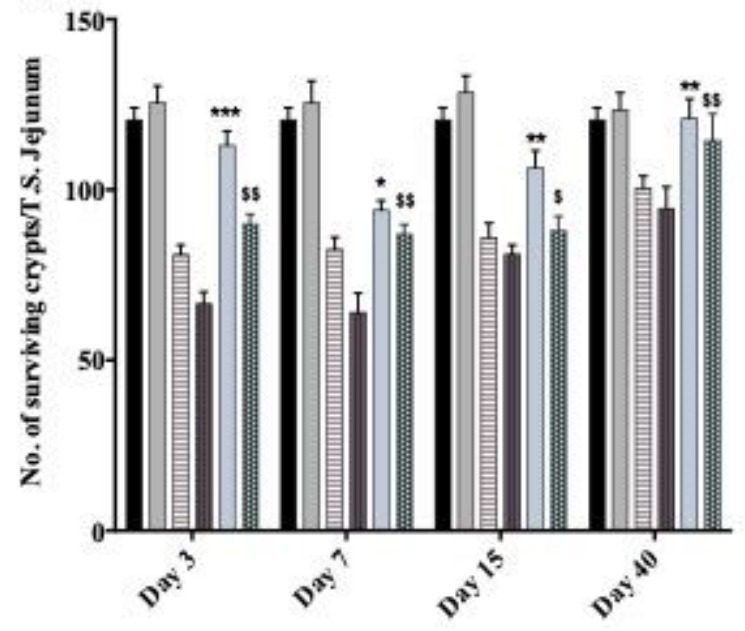

(b)
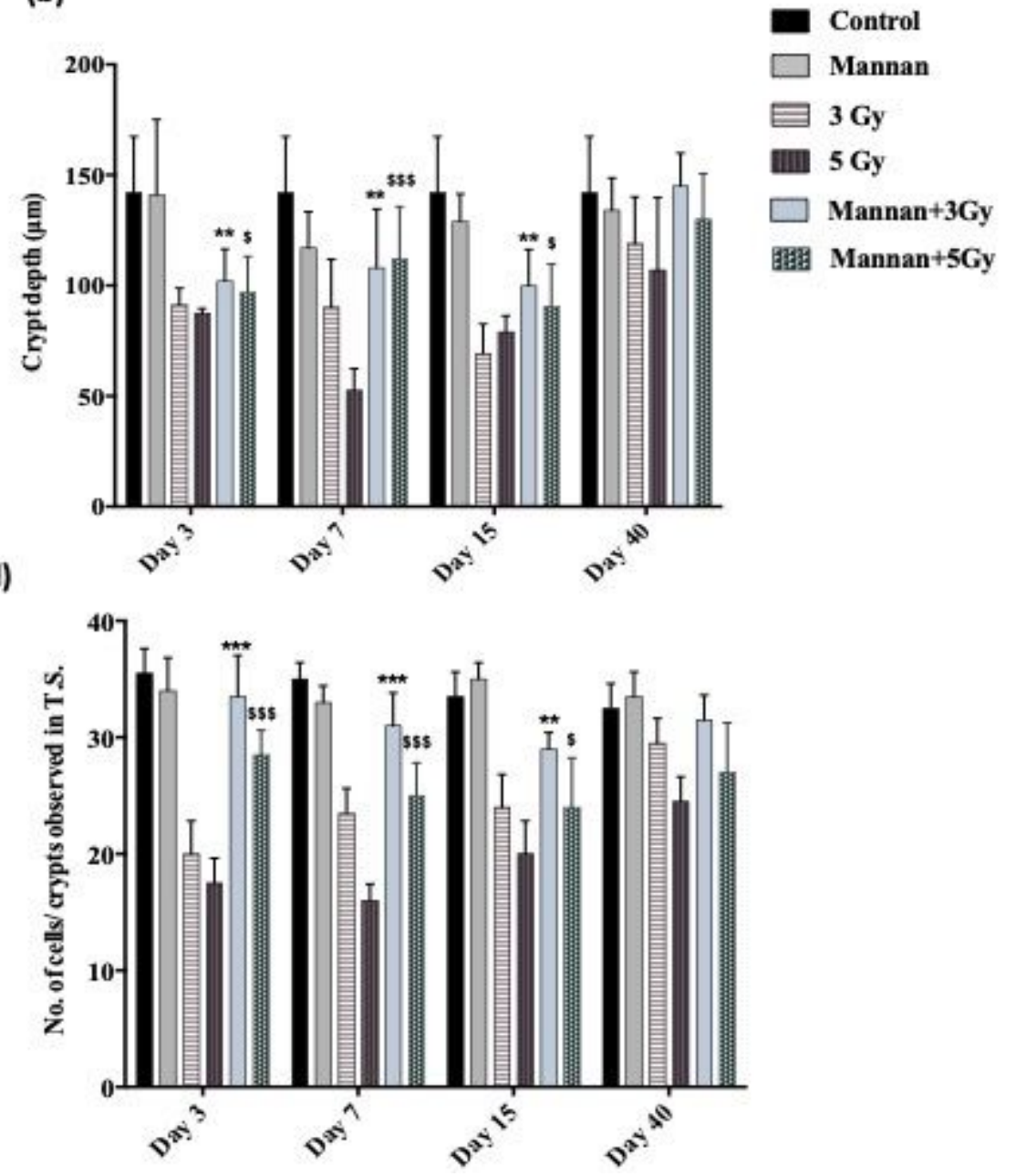

Figure 5

(a-d): Histological examination of small intestine: Mice were treated with MOS (200mg/kg bw) and/or subjected TBI (3 Gy and 5 Gy) and thereafter assessed for histological examinations of small intestine on days 3, 7, 15 and 40-post MOS treatment and/or TBI as described in materials and methods.

Representative images of (a) Villi height $(\mu \mathrm{m})(\mathrm{b})$ Crypt depth $(\mu \mathrm{m})(\mathrm{c})$ No. of surviving crypts/T.S. Jejunum (d) No. of cells present per crypt observed in T.S. Error bars represent mean $\pm S D$ and *p $<0.05$, ${ }^{* *} p<0.01$ and ${ }^{* * *} p<0.001$ was considered significant, *compared to 3 Gy irradiated control and \$ compared to 5 Gy irradiated control. 


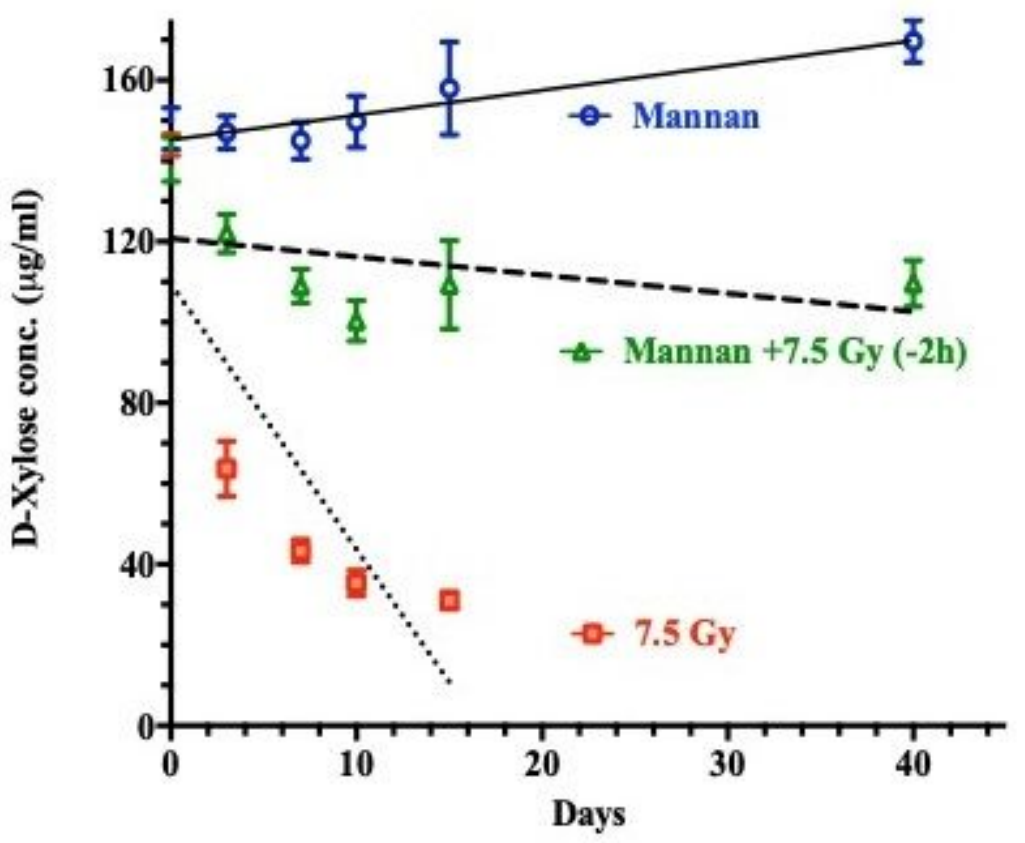

Figure 6

D-Xylose absorption assay: Mice were treated with MOS $(200 \mathrm{mg} / \mathrm{kg} \mathrm{bw})$ and/or subjected to lethal doses of TBI (7.5 Gy) assessed for absorptive capacity of the small intestine on days $0,3,7,10,15$ and 40 post $\mathrm{TBI}$ as described in materials and methods. Mice pretreated with MOS demonstrated significant recovery of xylose absorption post-TBI, when compared to TBI cohorts $(p<0.001)$.

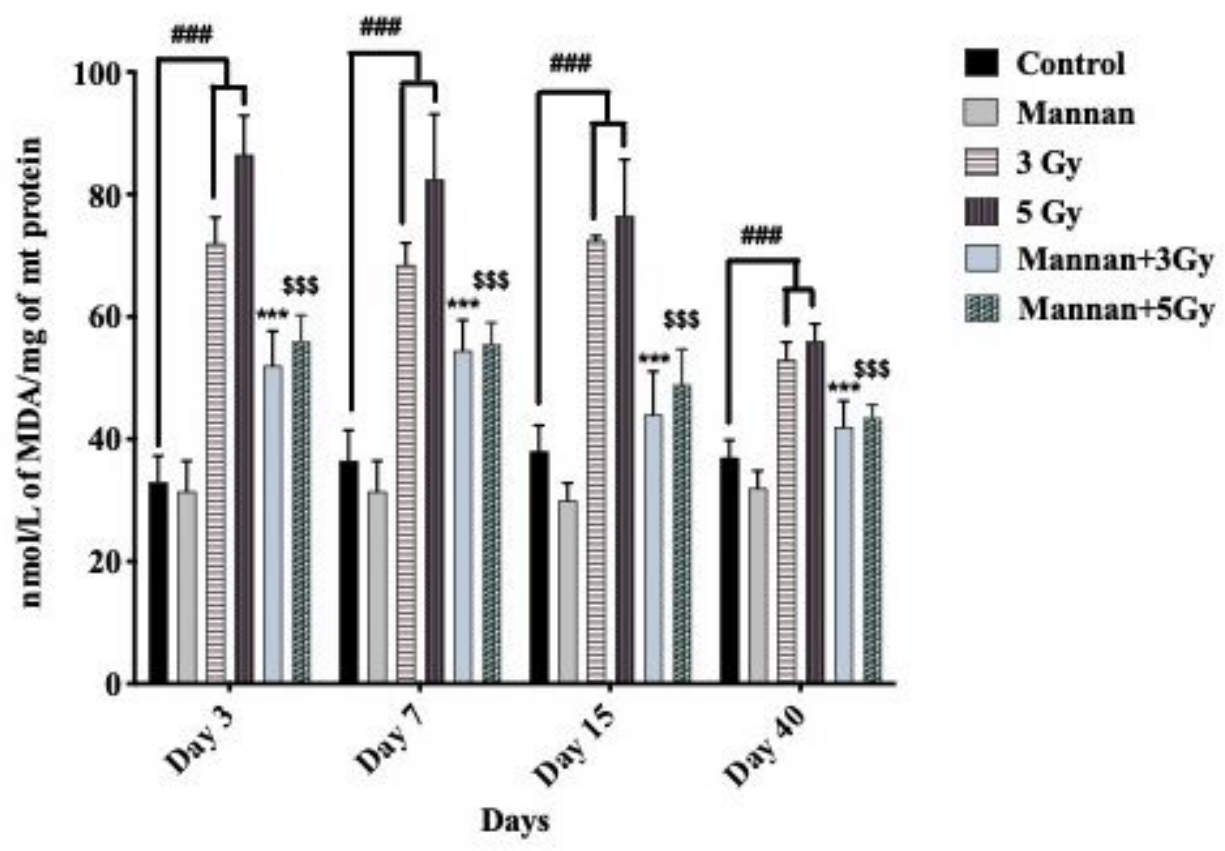

Figure 7 
Lipid peroxidation assay: Mice were treated with MOS $(200 \mathrm{mg} / \mathrm{kg}$ bw) and/or subjected TBI (3 Gy and 5 Gy) assessed for MDA levels in mice kidney mitochondria as described in materials and methods. Error bars represent mean \pm SD and ${ }^{\star \star \star} p<0.001$ was considered significant, \# compared to unirradiated control group, *compared to $3 \mathrm{~Gy}$ irradiated control and \$ compared to $5 \mathrm{~Gy}$ irradiated control.

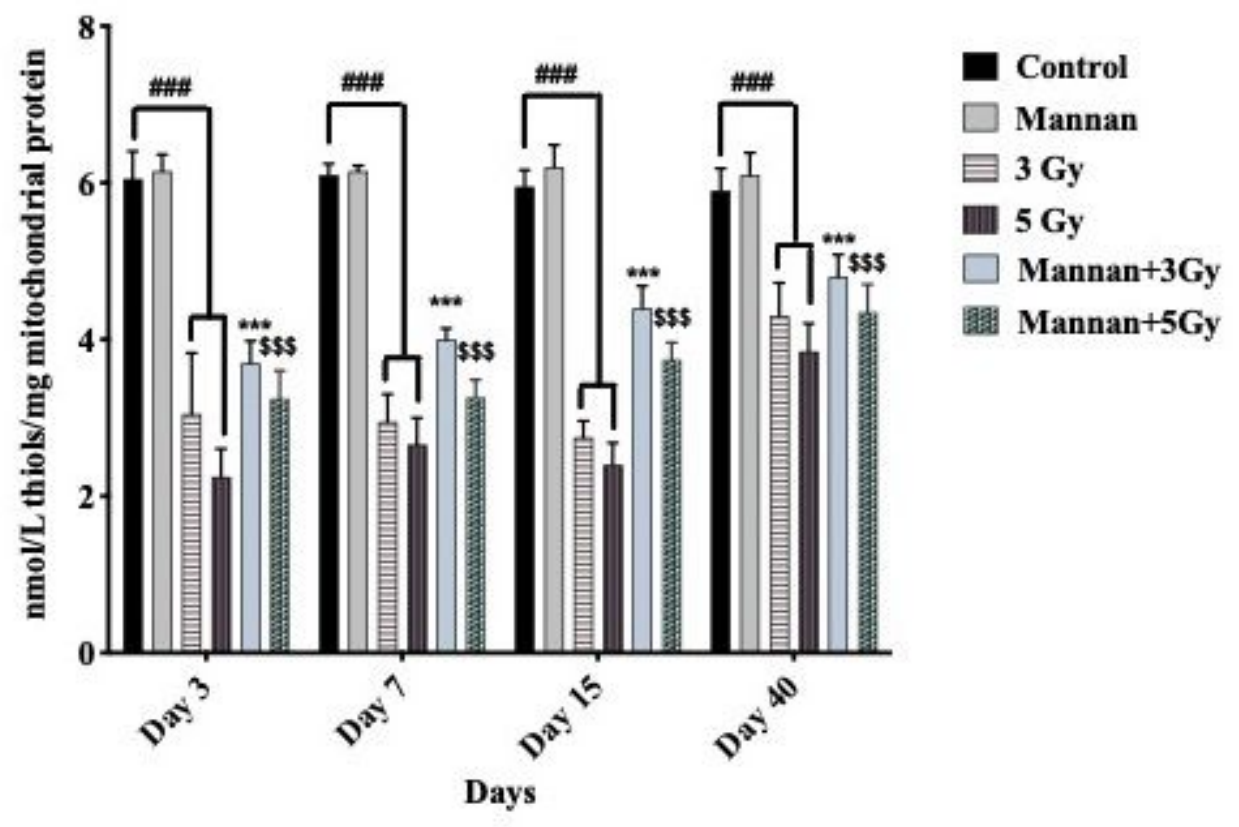

Figure 8

Total Thiol estimation using Ellman's reagent: Mice were treated with MOS $(200 \mathrm{mg} / \mathrm{kg} \mathrm{bw})$ and/or subjected TBI (3 Gy and $5 \mathrm{~Gy}$ ) and assessed for total thiol levels in mice kidney mitochondria as described in materials and methods. Error bars represent mean $\pm S D$ and $* \star \star p<0.001$ was considered significant, \# compared to unirradiated control group, *compared to $3 \mathrm{~Gy}$ irradiated control and $\$$ compared to $5 \mathrm{~Gy}$ irradiated control. 


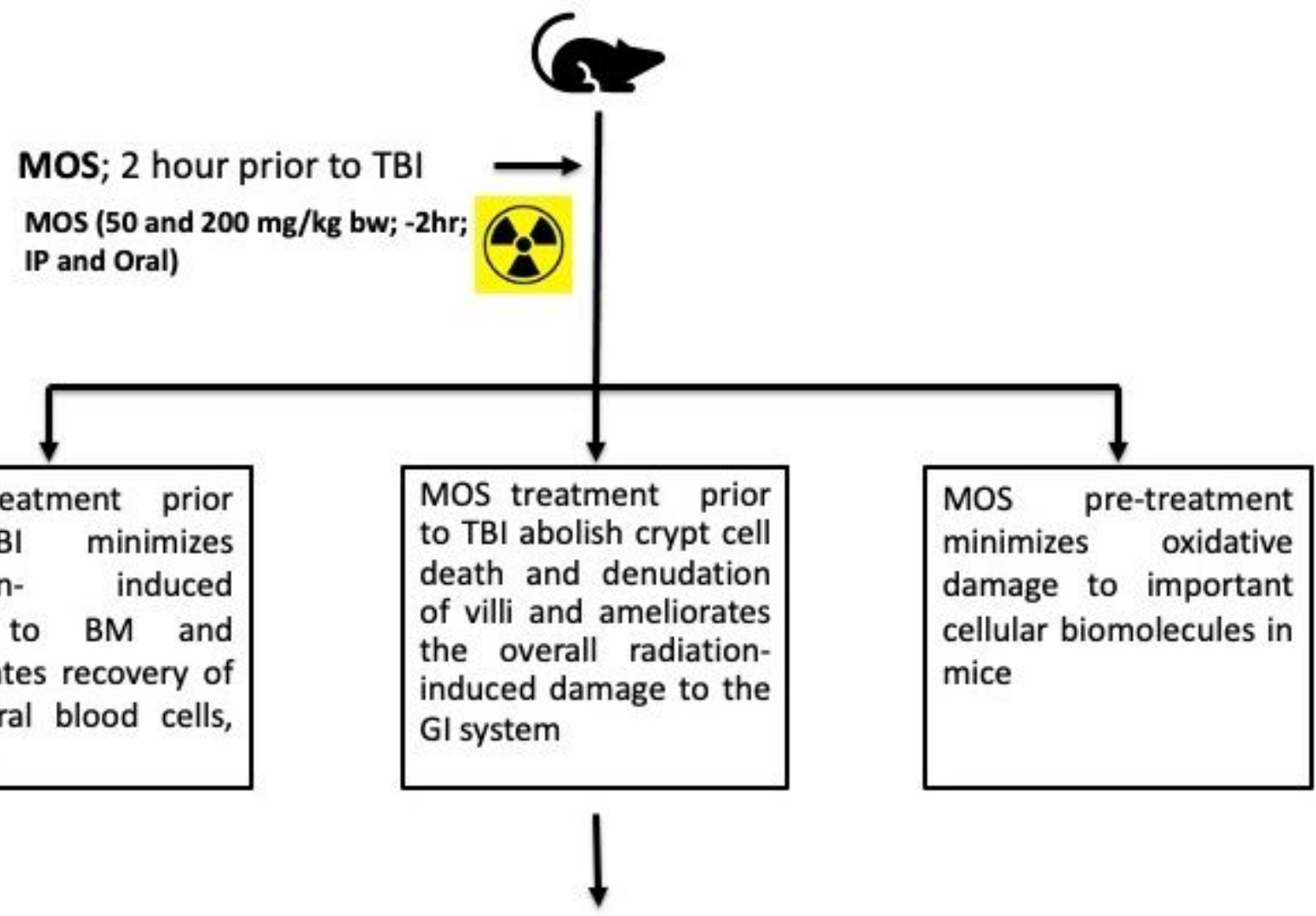

Administration of prior to $\mathrm{TBI}$ reverses $\mathrm{TBI}-$ induced lethality and provides $100 \%$ survival advantage, in mice.

Figure 9

MOS mediated radiation protection: MOS mediated radiation protection in normal cells requires TLR and ETC function. Under in vivo condition, MOS pretreatment abates radiation-induced damage, accelerates recovery and consequently abrogates TBI-induced lethality. 